\title{
O PÓS-POSITIVISMO COMO PRESSUPOSTO FILOSÓFICO DO NEOCONSTITUCIONALISMO
}

\author{
POST-POSITIVISM AS A PHILOSOPHICAL BASIS FOR \\ NEOCONSTITUTIONALISM
}

\author{
Angela Jank Calixto ${ }^{1}$ \\ Luciani Coimbra de Carvalho ${ }^{2}$
}

\section{RESUMO}

O pós-positivismo, ao atribuir normatividade aos princípios e defender a reinserção de valores morais no âmbito do direito, serviu de embasamento jusfilosófico para o neoconstitucionalismo. Para identificar a influência do neopositivismo nesse movimento do constitucionalismo contemporâneo, foram analisadas, através de uma pesquisa exploratória, descritiva, bibliográfica e dedutiva, as teorias que serviram de base à formação do pós-positivismo (jusnaturalismo e juspositivismo) e as principais ideias lançadas por importantes neopositivistas, como Dworkin e Alexy. Assim, verificou-se que o neoconstitucionalismo utiliza-se dos pensamentos pós-positivistas, pressupondo a instituição de valores morais no ordenamento jurídico e assegurando o primado da ética e justiça no direito.

Palavras-Chaves: Pós-positivismo; neoconstitucionalismo; jusnaturalismo; positivismo jurídico; valores morais.

\begin{abstract}
By attributing normativity to principles and defending the reinsertion of moral values within the law, the post-positivism theory served as a philosophical basis for neoconstitutionalism. To understand the influence of neopositivism in neoconstitutionalism, the theories that that served as basis for the formation of post-positivism (jusnaturalism and juspositivism) and the main ideas cast by important neopositivists, such as Dworkin and Alexy, were analyzed through an exploratory, descriptive, bibliographical and deductive research. Thus, it was found that neoconstitutionalism uses post-positivist ideas, presupposing the institution of moral values in the legal system and ensuring the supremacy of ethics and justice in law.
\end{abstract}

Keywords: Post- positivism; neoconstitutionalism; jusnaturalism; legal positivism, moral values.

\footnotetext{
${ }^{1}$ Mestranda em Direitos Humanos pela Universidade Federal de Mato Grosso do Sul - UFMS, Campo Grande, (Brasil).E-mail: angelajcalixto@gmail.com

${ }^{2}$ Doutora em Direito do Estado pela Pontifícia Universidade Católica - PUC, São Paulo, (Brasil). Professora Adjunta da Universidade Federal de Mato Grosso do Sul - UFMS, e da Graduação e Pós-Graduação. Professora do Mestrado Acadêmico em Direito da UFMS. E-mail: lucianicoimbra@ hotmail.com
} 


\section{INTRODUÇÃO}

No âmbito da teoria geral do direito, a identificação dos valores que devem ser protegidos pelo ordenamento, bem como o estudo da natureza jurídica da norma, da relação desta com a moral, dos critérios de validade das regras e princípios, entre outros aspectos, sempre foram de grande discussão entre teóricos em todas as partes do globo, sobretudo ante as constantes transformações sociais e a consequente modificação da forma de encarar a realidade jurídica.

É nesse sentido que se justifica o surgimento e a coexistência de diversas correntes de pensamento que tratam de forma diversificada aspectos relevantes do direito, entre as quais de destacam o jusnaturalismo, juspositivismo, realismo jurídico, utilitarismo e a teoria econômica do direito.

Com o fim da Segunda Guerra Mundial, observa-se no âmbito da teoria do direito o surgimento de uma nova corrente do pensamento contemporâneo, esta denominada de póspositivismo, para fazer frente às atrocidades cometidas durante a guerra, atrocidades estas justificadas pela aplicação estrita da legalidade, afastada de aspectos morais, conforme preconizado pela doutrina positivista predominante à época. Essa nova corrente de pensamento surgiu, pois, como forma de se superar os valores consagrados pelo positivismo jurídico, visando reintroduzir no campo do direito valores morais e conferir maior importância aos princípios, como era defendido à época do jusnaturalismo moderno.

Concomitantemente com o advento do neopositivismo, identifica-se, no campo do direito constitucional, o surgimento de um novo paradigma de interpretação constitucional, o neoconstitucionalismo, o qual, utilizando-se das ideias defendidas por teóricos pós-positivistas, consagra a introdução de aspectos materiais nas constituições nacionais, conferindo aos princípios e valores morais maior importância no ordenamento jurídico.

O neoconstitucionalismo define os novos delineamentos do direito constitucional contemporâneo, modificando a concepção de interpretação do direito ao introduzir aspectos materiais em âmbito constitucional e consagrar a superioridade da Constituição. Ante a importância de se compreender referido movimento constitucional, torna-se necessário um estudo acerca das ideias que possibilitaram seu surgimento, para que seja possível identificar em que sentido tais pensamentos pós-positivistas exercem influências nas constituições contemporâneas, o pós-positivismo constituindo o pressuposto filosófico do neoconstitucionalismo. 
Para tanto, serão analisadas, em um primeiro momento, as teorias que serviram de base à formação do pensamento pós-positivista, discorrendo-se acerca das teorias do jusnaturalismo e do juspositivismo, para entender em que aspecto o neopositivismo é identificado como uma corrente derivada da confluência de ambas as teorias. Após, serão apresentados os valores defendidos pelos pós-positivistas, em especial Dworkin e Alexy, para que se possa compreender como essa corrente se diferencia das anteriores, ao proporcionar a abertura do debate filosófico contemporâneo aos valores ético-políticos.

Por sim, serão analisadas as influências do pensamento pós-positivista no neoconstitucionalismo e de que modo ele se identifica como um novo marco filosófico do constitucionalismo contemporâneo.

Com relação ao procedimento metodológico, será realizada, quanto aos fins, uma pesquisa exploratória e descritiva, já que se buscará apresentar um panorama geral acerca das teorias do jusnaturalismo, do juspositivismo e, com um maior enfoque, do pós-positivismo, sendo utilizado o método dedutivo. Quanto aos meios, será realizada uma pesquisa bibliográfica, a partir de material coletado essencialmente de livros, artigos científicos, dissertações, teses de doutorado e revistas científicas.

\section{BASES PARA A FORMAÇÃO DO PÓS-POSITIVISMO}

Pode-se afirmar que o pós-positivismo corresponde a uma corrente de pensamento derivada da confluência de duas outras grandes correntes, cujas ideias exercem influências até hoje, quais sejam, o jusnaturalismo moderno e o positivismo jurídico. Estas, apesar de serem opostas uma à outra, são tidas, para os pós-positivistas, como complementares entre si.

Visto como a conjugação desses modelos puros de direito, o pós-positivismo é atualmente concebido como a mais influente corrente de pensamento a inspirar as constituições contemporâneas, já que defende pontos importantes de cada teoria anteriormente apontada, ao mesmo tempo efetuado uma leitura formal do direito e procurando reaproximar este da moral. Como ressalta Barroso:

A superação histórica do jusnaturalismo e o fracasso político do positivismo abriram caminho para um conjunto amplo e ainda inacabado de reflexões acerca do Direito, sua função social e sua interpretação. O pós-positivismo busca ir além da legalidade estrita, mas não despreza o direito posto; procura empreender uma leitura moral do Direito, mas sim recorrer a categorias metafísicas. [...] O pós-positivismo busca entrelaçar, sob uma nova roupagem, 
jusnaturalismo e juspositivismo, em que o comando normativo não mais prepondera dissociado de conteúdo moral externo (BARROSO, 2005, p. 0405).

Para que se possa entender, portanto, as ideias e valores defendidos pelos pós-positivistas, é necessário, primeiramente, que se entenda as duas grandes correntes de pensamento acima assinaladas, o contexto histórico em que surgiram e as ideias lançadas pelos principais teóricos de ambas as correntes. Somente assim é que se auferirão meios para entender em que sentido o pós-positivismo corresponde a uma confluência do juspositivismo e do jusnaturalismo moderno e de que modo tem influenciado o movimento constitucional contemporâneo.

Salienta-se, entretanto, que o objeto do presente trabalho não é esgotar o tema, apenas se buscando demonstrar os pensamentos de alguns teóricos mais importantes para as duas correntes de pensamento e identificar em que sentido suas ideias acabaram por servir de influência à doutrina pós-positivista.

Com relação ao jusnaturalismo moderno, cumpre frisar que essa teoria do direito surgiu, sobretudo, diante do advento do Estado Moderno, época na qual havia grande centralidade do poder nas mãos do soberano. Nesse período, a ideia da existência de um direito natural, o qual na Idade Média, influenciado pelas ideias de Santo Agostinho, era reconhecido como decorrente de uma força sobrehumana, sofreu grande modificação, para o fim de retirar do Direito a influência teológica e reconhecê-lo como decorrente da razão humana.

Decorrente da laicização da cultura moderna, o jusnaturalismo moderno estipulava que a verdade das ciências estava confiada à razão matemática e geométrica, a reta razão servindo como guia das ações humanas (BITTAR; ALMEIDA, 2015, p. 307).

Com os pensamentos de grandes teóricos como Hugo Grotius, Samuel Pudendorf e John Locke há uma mudança de centro com relação às épocas anteriores, a Ciência Jurídica deixando de estar ligada a concepções mítico-religiosas, para buscar seu fundamento último na razão humana (BITTAR; ALMEIDA, 2015, p. 308).

Frisa-se o pensamento de Grotius, cujas ideias inclusive serviram de inspiração à criação do Direito Internacional. Segundo o teórico, a validade da norma não é condicionada à lei divina, como defendido anteriormente, mas sim à concordância necessária entre a norma e a natureza racional e social, somente sendo concebido como justo aquilo que se encontra em concordância com referida natureza (GROTIUS, 2004). 
Diante disso, o autor defendia que o Direito Natural devia ser reputado como um mandamento da reta razão, que indica a necessidade moral inerente a uma ação qualquer, mediante o acordo ou o desacordo desta com a natureza racional (GROTIUS, 2004).

Também se destaca o pensamento de John Locke, segundo o qual convivem, simultaneamente, um Estado Civil e um Estado da Natureza, neste sendo apreendidos os direitos naturais, os quais para o autor não são inatos, mas de fácil apreensão pela razão, e aquele sendo criado pelo homem justamente para evitar o desrespeito e para assegurar a proteção daqueles direitos (BITTAR; ALMEIDA, 2015).

O que se evidencia é que apesar cada teórico possuir uma interpretação própria acerca do direito natural, todas defendiam um ponto em comum: o fato de o direito natural ser um ditame da reta razão, estritamente ligada aos valores morais. Não haveria separação, para os autores do período, entre o Direito Natural e o Direito Moral, apenas sendo válido o direito diretamente derivado da observância da moralidade humana.

Nessa fase, contudo, tais valores, ou melhor, princípios morais, apenas eram previstos de forma abstrata, a sua normatividade sendo basicamente nula, apenas havendo o reconhecimento de sua dimensão ético-valorativa.

O jusnaturalismo moderno, nesse sentido, ao aproximar a lei da razão, e pressupor a existência de princípios de justiça universalmente válidos, transformou-se na filosofia natural do Direito, constituindo o combustível das revoluções liberais que culminaram com a elaboração das Constituições escritas e as codificações (BARROSO, 2005).

Referidas revoluções e movimentos constitucionais, decorrentes dos reclames da sociedade por uma limitação do poder concentrado e ilimitado do soberano, acabaram por conferir uma grande importância à lei escrita, criando meios para o surgimento do pensamento positivista (FERNANDES; BICALHO, 2011).

Esclarece Barroso (2005) que o direito natural, ante o fato de não ser positivado, passou a ser considerado metafísico e anti-científico, de modo foi empurrado para a margem da história, em busca de uma maior objetividade e segurança jurídica.

Nesse cenário, o jusnaturalismo acabou por ceder lugar às correntes positivistas do direito. A lei passou a ser considerada como o único instrumento a legitimar a limitação dos direitos e a imposição de obrigações aos cidadãos. Adquiria a lei um novo status, passando ela a possuir mais importância que os postulados principiológicos, já que a sociedade necessitava 
princípios naturais (religiosos ou não). Nesse contexto, buscava-se segurança e objetividade do sistema, e o Direito positivo cumpriu bem esse papel (FERNANDES; BICALHO, 2011, p. 106).

Assim, valores morais e princípios não positivados no ordenamento jurídico foram relegados a um segundo plano, as normas de conduta ficando adstritas ao estabelecido na lei. A partir do juspositivismo, os princípios passam a possuir uma natureza meramente supletiva ou interpretativa, não sendo mais reputados, segundo defendido pelos jusnaturalistas, como valores superiores ou anteriores à lei. Segundo essa nova corrente de pensamento, os princípios podem ser inferidos do próprio sistema, seu valor derivando das próprias leis.

O positivismo jurídico, modernamente, originou-se dos pensamentos de Augusto Comte, este considerado por muitos como o fundador do positivismo jurídico, tendo em Hans Kelsen e em Herbert Hart seu apogeu.

É de grande importância a contribuição de Kelsen para o pensamento jurídico positivista, as ideias por ele defendidas em seu livro "Teoria Pura do Direito" ainda hoje sendo utilizadas como fundamento teórico do direito, tendo elas exercido grande influência nos pensamentos de teóricos pós-positivistas.

A questão de maior importância em sua teoria diz respeito ao conceito de validade do Direito. Para o autor, para que uma norma seja válida apenas é necessário que ela tenha sido criada de acordo com os procedimentos formais de criação previstos no ordenamento jurídico. A norma não se submete, pois, a um juízo valorativo, mas meramente formal, de modo que se determinado conteúdo foi positivado, deve ser entendido como reto e justo (KELSEN, 1998).

O fundamento de validade de uma norma, para Kelsen, só pode ser outra norma, todas as normas do ordenamento jurídico possuindo seu fundamento de validade último na norma fundamental (grundnorm). Esta corresponde a uma norma pressuposta, com conteúdo imediatamente evidente, as normas dela derivadas não sendo válidas em razão de possuírem determinado conteúdo, mas sim por terem sido criadas por determinada forma.

Assim, para o autor, todo e qualquer conteúdo pode ser direito, não sendo fornecido pela Teoria Pura do Direito qualquer critério de justificação ético-política. Assim, para Kelsen (1998), haveria uma separação entre o direito e a moral, o estudo do Direito devendo ser desprovido de valores, a moral devendo ser tida como extrínseca ao ordenamento jurídico. Como esclarece o teórico:

Se supusermos que Direito é, por sua essência, moral (tem caráter moral), então não faz qualquer sentido a exigência - feita sob o pressuposto da 
existência de um valor moral absoluto - de que o Direito deve ser moral [...] A exigência de uma separação entre Direito e Moral, Direito e Justiça, significa que a validade de uma ordem jurídica positiva é independente desta Moral Absoluta, única válida, da Moral por excelência, de $a$ Moral (KELSEN, 1998, p. 75)

Desta feita, uma ordem jurídica, mesmo que contrariasse alguns alicerces morais, seria válida: o Direito pode ou não ser moral, entretanto, o fato de este não ser justo, não retira a validade de determinado sistema jurídico (KELSEN, 1998). Desse modo, são apenas as leis postas que devem ser observadas na aplicação do Direito, podendo-se afirmar que a justiça restaria configurada na própria aplicação da lei, cabendo ao operador do direito aferir tão somente a validade formal da norma e não a justiça de sua aplicação.

Do mesmo modo, de grande relevância é a teoria formulada por Hart ${ }^{3}$, o qual, assim como Kelsen, propõe em sua obra "The concept of Law", a separação entre o Direito Moral e faz considerações, em especial, acerca dos critérios de validade da norma no ordenamento jurídico.

Em sua descrição do sistema jurídico, Hart trata da questão da validade das normas do ordenamento jurídico, reconhecendo a existência de uma regra de reconhecimento como fundamento último e critério supremo de validade de todas as demais normas (HART, 1996).

Para o autor, dizer que uma regra é válida significa afirmar que ela satisfaz todos os requisitos previstos pela regra de reconhecimento. É esta regra de reconhecimento, portanto, que estabelece os critérios através dos quais a validade das demais regras do sistema são avaliadas, estas apenas necessitando satisfazer tais requisitos para serem reputadas como válidas no ordenamento jurídico (HART, 1996).

No tocante à relação do direito com a moral, Hart, indo além das teorias juspositivistas que o precederam, assume a existência de uma relação inerente entre direito e moral, esclarecendo que a moral tem moldado o desenvolvimento do direito. $\mathrm{O}$ autor inclusive implantou a ideia do "conteúdo mínimo do direito natural”, este correspondente aos princípios de conduta reconhecidos universalmente e exigíveis para a viabilidade de qualquer organização social (HART, 1996).

\footnotetext{
${ }^{3}$ A posição originalmente adotada pelo autor foi revista, tendo Hart aceitando, após as críticas apontadas por Ronald Dworkin, a possibilidade de a regra de reconhecimento adotar algum aspecto material e moral, para evitar incorreções. Frisa-se, entretanto, que neste trabalho se discorre acerca do pensamento de Hart antes da introdução, pelo autor, do Pós-escrito em sua obra (O Conceito de Direito), já que esse estabelece características essenciais do movimento do positivismo jurídico.
} 
Em que pese tal fato, a constatação de que o desenvolvimento do direito foi influenciado pela moral, não nos permite concluir que o sistema jurídico, segundo as ideias defendidas por Hart, necessariamente deve se adequar a essa moral ou à justiça. Os critérios de validade jurídica de leis concretas de um sistema jurídico, pois, não necessariamente devem, na concepção de Hart (1996), incluir uma referência à moral ou à justiça.

Verifica-se, assim, que em todas as concepções positivistas do ordenamento jurídico a questão central gira em torno da segurança jurídica da aplicação da norma, enquanto o ponto relativo à justiça de aplicação de uma norma restringe-se a seu aspecto formal, ou seja, a sua validade formal (FERNANDES; BICALHO, 2011). Do mesmo modo, para os positivistas, ao contrário do estabelecido pelos jusnaturalistas, a moralidade é extrínseca ao direito, ao aplicador do direito não competindo a análise da justiça ou injustiça de uma norma.

Ocorre, entretanto, que ao equiparar o Direito à lei e afastá-lo das concepções de justiça, o positivismo serviu de norte ao cometimento de barbáries e atrocidades em meados do século XX, o que levou à decadência da corrente juspositivista. Sua decadência é emblematicamente associada à derrota do fascismo na Itália e do nazismo na Alemanha, nos quais foram promovidas barbáries sob a proteção da legalidade (BARROSO, 2005).

Desse modo, ao final da $2^{\mathrm{a}}$ Guerra Mundial, a ética e os valores começam a retornar ao Direito, levando ao surgimento de uma nova corrente de pensamento, qual seja, o póspositivismo, a qual, como destacado no início deste trabalho, se apresenta como uma confluência do jusnaturalismo e juspositivismo, retratando valores defendidos por ambas as correntes, como será visto a seguir.

\section{O PÓS-POSITIVISMO: UMA ANÁLISE A PARTIR DAS IDEIAS DE DWORKIN E ALEXY}

Com o fim de se transformar a política e impedir a ocorrência de novas atrocidades, surge um novo pensamento jusfilosófio, o pós-positivismo, para contrapor premissas positivistas que deixavam em segundo plano considerações de natureza axiológica, entre as quais os princípios (SILVA, 2014), e que acabaram por justificar, pela aplicação estrita da legalidade sem a observância aos aspectos morais do direito, o cometimento de barbáries no período correspondente à Segunda Guerra Mundial. 
Passa-se a defender a necessidade de haver um relacionamento estreito entre o direito e a moral, bem como a reintrodução dos princípios da justiça, da dignidade da pessoa humana, da razoabilidade e da proporcionalidade no direito.

Assim, como destaca Faralli (2006, p. 11), a partir da queda da distinção entre direito e moral, a qual prevalecia durante o positivismo jurídico "abre-se um novo caminho para uma filosofia do direito normativa, empenhada em questões de grande repercussão política e moral, em estreita conexão com a filosofia política e a filosofia moral”.

Importante modificação no tocante à doutrina anterior (positivismo) se dá com relação ao valor dos princípios. A partir do pós-positivismo, as novas Constituições dos Estados passam a aceitar a hegemonia axiológica dos princípios, estes sendo considerados de fundamental importância nos novos sistemas constitucionais (BONAVIDES, 2009, p. 264).

Desse modo, com o neopositivismo, os valores passam a permear o sistema tanto no momento da confecção da norma como durante a aplicação da mesma (FERNANDES; BICALHO, 2011), legitimando-se a utilização de parâmetros de justiça e equidade para a resolução dos casos submetidos à apreciação do aplicador do direito, ante a abertura valorativa do sistema jurídico.

Passa-se, portanto, à utilização tanto de aspectos do jusnaturalismo, por se defender uma aproximação do direito com a moral (o que não era reconhecido pelos positivistas), quanto de aspectos do juspositivismo, ao se pressupor a normatividade dos princípios e, consequentemente, dos valores morais (ao contrário do estabelecido no jusnaturalismo, no qual os princípios apenas eram previstos de forma abstrata).

Como principais teóricos desse novo movimento, temos Ronald Dworkin (Taking rights seriously, 1977), John Rawls (A theory of justice, 1980), Gustavo Zagrebelsky (El derecho ductil, 1992) e Robert Alexy (Teoria de los derechos fundamentales, 1985). Destaca-se que apesar de cada teórico possuir uma concepção própria acerca do direito e da relação desse com a moral, suas ideias não se inserindo em um movimento unitário, é possível identificar características comuns entre suas ideias, sobretudo ante o fato de que "relativizam a separação entre o Direito e a Moral, admitindo critérios materiais de validade das normas" (VALE , 2009, p. 47).

Insta salientar que a abertura do debate filosófico contemporâneo aos valores éticopolíticos teve como um de seus resultados o surgimento do neoconstitucionalismo, como se verá no próximo tópico. A identificação do constitucionalismo como teoria específica do direito e sua distinção do positivismo jurídico foi proposta por Robert Alexy (1993), o qual se inspirou 
nas ideias de Ronald Dworkin (1977) (FARALLI, 2006, p. 11-12). Assim, tendo em vista o objetivo desse trabalho, analisar-se-á as teorias de referidos doutrinadores, para que se possa entender em que sentido elas se diferenciam das correntes anteriormente analisadas e se constituem como marco filosófico do neoconstitucionalismo.

O novo constitucionalismo surgiu contemporaneamente às críticas de Dworkin ao positivismo da década de 1960. O autor faz um ataque geral ao positivismo, como ele mesmo afirma em sua obra, utilizando-se da versão de Hart como alvo. Ao questionar a tese hartiana da separação entre direito e moral, defende não ser possível diminuir os ordenamentos jurídicos a meras estruturas normativas, estabelecendo que, ao lado das regras, existam os princípios, os quais transcendem o direito estatuído (DWORKIN, 2002).

Ressalta o teórico que o positivismo jurídico fracassou, essencialmente, em razão de os teóricos ignorarem o fato crucial de que os problemas da teoria do direito são, na realidade, problemas relativos a princípios morais e não a estratégias ou fatos jurídicos. Desse modo, defende que para qualquer teoria ser bem sucedida, deve-se trazer à luz tais problemas e enfrentá-los como problemas de teoria moral (DWORKIN, 2002).

Ao contrário do pensamento positivista, Dworkin (2002) assevera que no caso de os juízes se depararem com os chamados "casos difíceis", ou seja, aqueles casos em que os juristas não encontram no ordenamento jurídico posto qualquer regra que poderia ser aplicada, não se deve conferir a eles um poder discricionário para decidirem o caso como bem entenderem, legislando novos direitos jurídicos e aplicando-os retroativamente.

Em sua teoria, mesmo quando não ha nenhuma regra que regula o caso, o juiz continua a ter o dever, mesmo nos casos difíceis, de descobrir quais são os direitos das partes, e não inventar novos direitos retroativamente. Nesse sentido, devem os juízes buscar uma decisão, para o caso concreto, em princípios, estes tidos como de observância obrigatória na teoria de Dworkin. Assim, não haveria criação do direito pelo juiz no exercício de seu poder discricionário, já que este não possui competência para tanto, havendo apenas a descoberta por ele de qual o direito (aqui compreendidos os princípios) que deve ser utilizado no caso concreto.

Desta feita, o autor passa a reinserir os princípios como normas jurídicas vinculantes, asseverando que estes devem ser tratados da mesma maneira que as regras, sendo eles, portanto, integrantes do direito e possuindo obrigatoriedade de lei. Reconhece-se, pois, a possibilidade de tanto uma constelação de princípios como uma regra positivamente imposta estabelecer uma obrigação legal (DWORKIN, 2002). 
Ante o fato de se atribuir normatividade aos princípios, passa o autor, então, a diferenciar estes das regras, esclarecendo que a diferença entre eles se dá, sobretudo em razão de os princípios possuírem uma dimensão de peso, que as regras não possuem. Em razão dessa dimensão, diante de um caso concreto, pode ser que mais de um princípio - igualmente válido, dada sua estrutura lógica - tenda a conduzir a decisão em sentidos diversos, situação em que o julgador deverá avaliar qual desses padrões possui, no caso, maior peso, força e importância (DWORKIN, 2002).

Em sentido contrário, as regras devem ser aplicadas "à maneira tudo ou nada" (DWORKIN, 2002, p. 39). Quando um fato se subsume à regra, ela deve ser aplicada; caso contrário, não gera qualquer efeito, não contribuindo para a decisão. Assim, se duas regras entrarem em conflito, uma delas não pode ser regra válida. A decisão acerca de qual será válida e qual deverá ser abandonada ou reformada fica sujeita a considerações exteriores às próprias regras (DWORKIN, 2002)

Verifica-se que, para Dworkin (2002), a moralidade encontra-se evidente no direito, ante o fato de os princípios possuírem força normativa. O princípio, para ou autor, é um padrão que deve ser observado porque é uma exigência de justiça ou equidade ou alguma outra dimensão de moralidade.

Dessa forma, na teoria de Dworkin, a normatividade dos princípios aparece como condição de existência da normatividade do ordenamento jurídico como um todo, representando a dimensão moral da evolução do direito.

Do mesmo modo, Robert Alexy, em sua obra “Teoria dos Direitos Fundamentais”, bem como em livros posteriores, como o "Conceito e a Validade do Direito", também defendeu a normatividade dos princípios, bem como a conexão conceitual e normativamente necessária entre o direito e a moral.

Alexy, aprimorando a teoria de Dworkin, procura fazer uma distinção entre princípios e regras, identificando aqueles como uma espécie normativa qualitativamente distinta das regras. Apesar de utilizar-se das ideias de Dworkin para a formulação de sua própria teoria, entretanto, aduz que referido autor não chegou ao núcleo da distinção entre regras e princípios, núcleo este que consiste no fato de os princípios deverem ser vistos como mandados de otimização, que significa que "son normas que ordenan que algo sea realizado en una medida lo mayor posible dentro del marco de las posibilidades fácticas e jurídicas"4 (ALEXY, 2009, p. 185). O autor

\footnotetext{
${ }^{4}$ São normas que ordenam que algo seja realizado na maior medida possível dentro do marco das possibilidades fáticas e jurídicas (tradução nossa).
} 
parte do pressuposto, portanto, de que entre os princípios e regras não há tão somente uma distinção de grau, mas também de qualidade.

Essa distinção entre regras e princípios constitui a base do argumento de Alexy em favor da instituição de um constitucionalismo moderado, em que tanto as regras quanto os princípios são normas de observância obrigatória.

Segundo o autor, os princípios, mais genéricos e abstratos, podem ser definidos como "preceitos de otimização", ou seja, como diretrizes realizáveis apenas em parte e em medida variável, que não prescrevem condutas específicas, mas remetem a valores que deverão ser efetivados na maior medida possível (ALEXY, 2008). Dessa forma, podem ser cumpridos em diferentes graus, exigindo-se a aplicação da técnica da ponderação para sua adequada aplicação.

As regras, por sua vez, "são normas que são sempre satisfeitas ou não satisfeitas. Se uma regra vale, então, deve se fazer exatamente aquilo que ela exige; nem mais, nem menos" (ALEXY, 2008, p. 91). Ou seja, se ocorre a subsunção do fato à regra, seus efeitos devem ser produzidos exatamente como determinado na própria regra, devendo esta ser aplicada integralmente.

Onde a distinção entre regras e princípios desponta com mais nitidez é ao redor da colisão de princípios e do conflito de regras. Havendo conflito de regras, este apenas pode ser resolvido se houver uma cláusula de exceção que remova o conflito ou se uma das regras for declarada nula. Já no caso de colisão de princípios, a situação é totalmente diferente. Nesse caso, a colisão ocorre se algo é vedado por um princípio, mas permitido por outro, hipótese em que um dos princípios deve recuar. Isto, porém, não significa que o princípio do qual se abdica seja declarado nulo, nem que uma cláusula de exceção nele se introduza. $\mathrm{O}$ que vai determinar qual o princípio que deve ceder serão as circunstâncias do caso (ALEXY, 2008).

Assim, um princípio cede ao outro em determinadas circunstâncias e, em situações distintas, a questão da prevalência se pode resolver de forma contrária. Com isso, se quer dizer que os princípios têm um peso diferente nos casos concretos, e que o princípio de maior peso é o que prepondera. Nesse sentido é que se afirma que os princípios instituem obrigações prima facie, já que podem eles ser superados, ou terem reduzido seu âmbito de abrangência em face da colisão com outro princípio no caso concreto.

Dessa forma, verifica-se que os conflitos de regras se desenrolam na dimensão de validade, ao passo que a colisão de princípios transcorre fora dessa dimensão de validade e dentro da dimensão do peso, ou seja, do seu valor. 
As ideias de Dworkin e Alexy mostram-se relevantes ao se propor, por meio da distinção entre princípios e regras, ambas de caráter normativo, uma reviravolta em relação ao positivismo, que passa a considerar a presença dos princípios no processo de aplicação e interpretação do direito.

Do mesmo modo defende Zagrebelsky (2007), para quem a realidade adquire valor ao se colocar em contato com os princípios, os quais passam a ter qualidades jurídicas próprias. Segundo o autor:

El valor se incorpora al hecho e impone la adopción de "tomas de posición" jurídicas conformes com el (al legislador, a la jurisprudência, a la administración, a los particulares y, em general, a los intérpretes del derecho). El "ser" iluminado por el principio aún no contiene em si el "deber ser", la regla, pero sí indica al menos la dirección en la que debería colocarse la regla para no contravenir el valor contenido en el principio (ZAGREBELSKY, 2007, p. 118). ${ }^{5}$

Identifica-se, nesse sentido, as principais características desse novo posicionamento teórico, como a) a abertura valorativa do sistema jurídico; b) a consideração tanto dos princípios quanto das regras como normas jurídicas; c) a identificação da Constituição como o locus principal dos princípios; e d) o aumento da força política do Judiciário em face da constatação de que o intérprete cria norma jurídica (FERNANDES; BICALHO, 2011).

Tais ideias são de essencial importância, ante o fato de reaproximarem o direito aos ideais de justiça, levando ao ressurgimento da noção de que a esta deve ser buscada na criação, aplicação e interpretação da norma, não mais se admitindo o isolamento do aplicador do direito com relação aos valores que sustentam o direito.

Desse modo, ao inserir os princípios como valores fundamentais no direito, reaproximando o direito da moral, os pensamentos pós-positivistas, acabaram por servir de embasamento jusfilosófico para um movimento no âmbito do Direito Constitucional que se desenvolvia concomitantemente ao surgimento dos pensamentos pós-positivistas, qual seja, o neoconstitucionalismo.

\section{AS INFLUÊNCIAS DO PÓS-POSITIVISMO NO NEOCONSTITUCIONALISMO}

\footnotetext{
${ }^{5} \mathrm{O}$ valor se incorpora ao feito e impõe a adoção de "tomadas de posição" jurídicas conformes com ele (ao legislador, à jurisprudência, à administração, aos particulares e, em geral, aos intérpretes do direito). O "ser" iluminado pelos princípios ainda não contém em si o "dever ser", a regra, mas sim indica ao menos a direção em que a regra deveria colocar-se, para não contradizer o valor contido no princípio (tradução nossa).
} 
O marco histórico do novel direito constitucional, o qual surgiu na Europa continental, foi o constitucionalismo do pós-guerra, o qual, inspirado nas ideias sedimentadas pela teoria do pós-positivismo, contrapôs-se ao constitucionalismo clássico, no qual a Constituição, em que pese sua relevância simbólica, detinha nítido caráter instrumental, figurando como reflexo do ideário liberal absenteísta.

Ante o fato de o padrão absenteísta do constitucionalismo clássico ser insuficiente para lidar com a crescente complexidade das relações sociais e a conflituosidade desta derivada, o conceito clássico de Constituição, de matiz instrumental-liberal foi colocada em cheque, cedendo lugar a novas concepções sobre sua estrutura, natureza e finalidade (VIEIRA, 2013).

É nesse sentido que se lançam as bases para a conformação de um novo paradigma de interpretação constitucional no período pós-guerra, não mais ligado à ideia de limitação do poder do Estado, mas sim pela busca da defesa do conteúdo material da Constituição.

A partir de então, consagra-se a ideia de supremacia da Constituição, fórmula esta envolvida pela constitucionalização dos direitos fundamentais. Há uma ruptura com o constitucionalismo liberal de previsão meramente formal do direito, objetivando-se a garantia material de direitos fundamentais a todos (VALE, 2009). Como bem elucida Silva:

\footnotetext{
Enquanto o constitucionalismo, historicamente, ocupava-se da consolidação dos pilares do Estado de Direito, especialmente o modelo de organização política e a declaração de direitos, de maneira a prescrever, sobretudo, segurança jurídica, permanecia reservado às codificações o desiderato de regrar as relações sociais. Em outras palavras, competia mais aos códigos disciplinar as obrigações contraídas reciprocamente entre os indivíduos, enquanto a Carta Magna estava direcionada a regular as questões estruturais do Estado. Em contraponto, o neoconstitucionalismo pôs no centro da experiência jurídica a Constituição, como pressuposto sine qua non à efetividade e juridicidade do direito em toda a sua manifestação, quer no ambiente público, quer no ambiente privado (SILVA, 2014, p. 175)
}

A identificação do constitucionalismo e, consequentemente, do neoconstitucionalismo, como uma teoria específica do direito e a sua distinção do positivismo foi proposta por Alexy (influenciado pela ideias de Dworkin, como visto) no final dos anos 1980, ante o debate sobre o papel do Tribunal Constitucional Federal na Alemanha e a interpretação conferida a sua jurisprudência (FARALLI, 2006).

A partir de então se reconhece o aumento da complexidade da estrutura normativa dos sistemas constitucionais contemporâneos, sobretudo diante da introdução dos princípios em 
sede constitucional e da distinção destes das regras em geral (FARALLI, 2006), pensamento este defendido pelos teóricos positivistas, como visto.

É importante esclarecer, neste ponto, que apesar de o neoconstitucionalismo estruturar-se sob a perspectiva filosófica do pós-positivismo, com este não se confunde.

Pode-se definir o neoconstitucionalismo como um movimento jurídico-político-filosófico que modifica a concepção de interpretação do Direito, ao introduzir conceitos axiológicos e ao atribuir força normativa à Constituição, reposicionando-a como principal elemento na ordem jurídica (VALE, 2007, p. 138).

Conforme conceito atribuído por Möller (2011, p. 23), o neoconstitucionalismo abarca práticas judiciais do constitucionalismo contemporâneo, podendo significar "um movimento ideológico nascido no âmbito jurídico, que propõe alguns câmbios de atitude na aplicação das normas constitucionais e de alteração do papel dos juízes na formação do direito".

O neoconstitucionalismo busca definir os novos delineamentos do direito contemporâneo, reinserindo os princípios e a moral no âmbito da Constituição. Aquilo que distingue o neoconstitucionalismo é a adoção de um peculiar modelo constitucional, este sendo concebido como um "modelo axiológico da constituição concebida como norma" (POZZOLO, 1998).

Com o advento desse movimento, a norma constitucional apenas pode ser assim determinada em razão do particular conteúdo que expressa, e não mais em razão do sujeito que redigiu o documento. A observância da Constituição, com o novo movimento constitucional, se deve ao fato de esta justificar-se em normas de caráter superior, pautadas em valores morais (POZZOLO, 1998).

Já o pós-positivismo, como já destacado, é o embasamento da filosofia do direito, a matriz jusfilosófica para o neoconstitucionalismo. Como ressaltam Fernandes e Bicalho (2011), o póspositivismo se constitui como a concepção teórica do neoconstitucionalismo, pois permite repensar alguns alicerces jurídicos, como a teoria da norma (já que passa a defender a inclusão da normatividade dos princípios), a teoria das fontes (visto que os princípios deixam de ser fontes secundárias, para serem fontes primárias capazes de regular condutas) e a teoria da interpretação (tópica, hermenêutica e argumentação jurídica).

O neoconstitucionalismo propõe, assim, a instituição nos Estados das premissas do póspositivismo, no qual prepondera a convergência normativo-axiológica entre o direito e a moral. O instante atual é marcado pela superioridade da Constituição, bem como pela absorção de valores morais e políticos (fenômeno por vezes designado como materialização da 
Constituição), sobretudo em um sistema de direitos fundamentais autoaplicáveis (MENDES; BRANCO, 2014, p. 59).

Insta salientar que apesar de haver mais de uma modalidade de neoconstitucionalismo, Comanducci (2003) ressaltando que este pode ser dividido em três modalidades diversas (neoconstitucionalismo metodológico, teórico e ideológico) o objetivo desse trabalho não é discorrer acerca dos pontos divergentes entre as diversas teorias existentes, mas sim identificar os pontos comuns e demonstrar em que sentido o pós-positivismo exerceu importantes influências nesse novo movimento do Direito Constitucional.

Vale (2009) ressalta que apesar das particularidades de cada modalidade de neoconstitucionalismo, todas apresentam pontos em comum: o reconhecimento da materialidade e a reforma da ideia de supremacia da Constituição; a necessidade de positivação, implementação e garantia dos direitos fundamentais; a existência de princípios e regras na ordem jurídica e na Constituição; e a importância na interpretação da Constituição.

Do mesmo modo, estabelece Feralli (2006), o qual ressalta que essa abordagem constitucionalista do direito é caracterizada por três aspectos principais: a correção moral do direito ocupa papel central nesta teoria, havendo a inclusão de conteúdos morais no direito, expressos nos princípios e nos direitos invioláveis dos indivíduos; a atribuição de uma maior importância aos processos de aplicação do direito; e a vinculação do legislador aos princípios e aos direitos constitucionais, bem como o papel decisivo dos juízes para sua execução, mesmo em contraste com as decisões legislativas e com a lei.

Dessa forma, com o fenômeno do neoconstitucionalismo, verifica-se algumas mudanças fundamentais. Como apontado por Ávila, há

[...] princípios em vez de regras (ou mais princípios do que regras); ponderação no lugar de subsunção (ou mais ponderação que subsunção); justiça particular em vez de justiça geral (ou mais análise individual e concreta do que geral e abstrata); Poder Judiciário em vez dos Poderes Legislativo ou Executivo (ou mais Poder Judiciário e menos Poderes Legislativo e Executivo); Constituição em substituição à lei (ou maior, ou direta, aplicação da Constituição em vez da lei) (ÁVILA, 2014, p. 02).

O movimento constitucionalista contemporâneo, influenciado pelas ideias póspositivistas, portanto, surge para contrapor premissas positivistas, as quais relegavam os princípios constitucionais a um segundo plano, dando primazia à lei infraconstitucional e ignorando postulados morais. 
Desse modo, como explica Ferrajoli, com a introdução de princípios em sede constitucional, há uma reaproximação do direito às ideias jusnaturalistas:

Com a incorporação nas Constituições de princípios de justiça de caráter éticopolítico, como a igualdade, a dignidade das pessoas e os direitos fundamentais, desaparece o principal traço distintivo do positivismo jurídico: a separação entre direito e moral, ou seja, entre validade e justiça. Segundo esta tese, a moral, que no velho paradigma juspositivista correspondia a um ponto de vista externo ao direito, agora faria parte de seu ponto de vista interno (FERRAJOLI, p. 96).

Destaca-se, entretanto, que apesar de se utilizar das ideias jusnaturalistas de aproximação do direito à moral, com esta corrente não se confunde, visto que no neopositivismo os princípios (e, consequentemente, os valores neles consagrados) passam a ter aspecto normativo, de modo a garantir a segurança jurídica defendida pelos positivistas.

Denota-se, pois, que o movimento neocontitucionalista pressupõe a instituição no ordenamento jurídico dos valores defendido por Dworkin e Alexy, já que confere valor normativo aos princípios, propõe uma estreita relação entre o direito e a moral, atribui maior importância aos preceitos materiais insculpidos na Constituição e, ao preconizar a ponderação em detrimento da mera subsunção, privilegia a análise concreta, para garantir que, em cada caso particular seja assegurada a observância aos ideais de justiça.

Importante contribuição desse novo modelo de Estado constitucional, e que acaba por diferenciar as novas constituições das anteriores, decorre justamente do fato de se encerrar princípios em seu interior, atribuindo a eles importância primordial. O reconhecimento de normatividade de tais princípios e sua distinção com relação às regras é característico do póspositivismo, como já destacado, e é a partir deles que se expressam decisões valorativas que se impõem ao legislador e aplicador do direito.

A importância conferida aos princípios corrobora a tendência irresistível que conduz à valoração e eficácia dos princípios como normas-chaves de todo o sistema jurídico (BONAVIDES, 2009). Tal importância, como defendido nas teorias de Dworkin e Alexy, se torna mais evidente pelo fato de os princípios apresentarem-se como os pontos axiológicos de mais alto destaque e prestígio nas Constituições contemporâneas.

Como destaca Alexy (2009, p. 176), para o qual a inclusão dos princípios em sede constitucional constitui um dos pontos mais importantes de sua teoria, a inserção de princípios e, consequentemente, valores no sistema jurídico é imprescindível, como exigência do próprio 
Estado constitucional democrático, estes principios devendo ter "si no exclusivamente si en una buena parte su ubicación jurídico positiva en la Constituición". 6

Desse modo, os valores ingressam no sistema jurídico a partir dos princípios, deixando eles de deter caráter supletivo, para ocupar posição de destaque no ordenamento jurídico. Como destaca Bonavides (2009), os princípios deixam de ter caráter meramente supletivo ou subsidiário, sendo eles colocados no ponto mais alto da escala normativa, visto que ligados a valores morais.

A partir do novo movimento do Direito Constitucional, os princípios passam da especulação metafísica para o campo concreto de direito positivo; deixam de ser previstos apenas nos Códigos para ingressarem nas Constituições (passagem da esfera jusprivatista para a esfera juspublicística); passam à esfera da Ciência Jurídica, deixando de ser tratados apenas na esfera jusfilosófica; ganham caráter normativo; e passam a deter total hegemonia e preeminência nas Constituições. Conforme ressalta Bonavides, ao tratar da importância dos princípios no ordenamento jurídico:

Fazem eles a congruência, o equilíbrio e a essencialidade de um sistema jurídico legítimo. Postos no ápice da pirâmide normativa, elevam-se, portanto, ao grau de norma das normas, de fontes das fontes. São qualitativamente a viga-mestra do sistema, o esteio da legitimidade constitucional, o penhor da constitucionalidade das regras de uma Constituição (BONAVIDES, 2009, p. 294).

Assim, ante a abertura valorativa do sistema constitucional e a inserção dos princípios no texto constitucional como valores máximos a serem buscados, estes proporcionados pelas ideias e perspectivas dos pós-positivismo, desenvolvem-se soluções pertinentes à solução de problemas constitucionais contemporâneos.

Essa inserção dos princípios nas constituições como parâmetros de observação obrigatória, e o consequente estabelecimento de uma nova relação entre o direito e a moral escoa do marco filosófico do novo direito constitucional, o pós-positivismo, influenciado em especial pela ideias de Dworkin e Alexy.

Desse modo, no neoconstitucionalism algumas estruturas básicas do constitucionalismo clássico são modificadas, tais como a previsão meramente estrutural e formal do direito, para inserir aspectos de conteúdo material em âmbito constitucional, ante a atribuição de maior carga

\footnotetext{
${ }^{6}$ [...] se não exclusivamente, ao menos em boa parte, sua localização jurídico-positiva na Constituição (tradução nossa).
} 
valorativa aos princípios constitucionais, estes reconhecidos como normas de observação obrigatória.

Como consequência, nesse novo modelo de constitucionalismo, compete ao operador do direito, quando da interpretação e resolução das controvérsias, sempre observar se as respostas se coadunam com os princípios constitucionais, cabendo ao intérprete, em cada caso concreto, a identificação do peso a ser atribuído a cada princípio, para que assim seja assegurada a predominância dos valores éticos e de justiça.

Essa face pós-positivista do neoconstitucionalismo implica grande importância da ciência jurídica moderna (SILVA, 2014), sobretudo ante o fato do reconhecimento da supremacia da Constituição em face do ordenamento jurídico e da inserção de princípios como normas jurídicas que imprimem valores morais a serem observados.

Afasta-se a interpretação apenas da norma positivada, para impor a observância pelo legislador e aplicador do direito da complexidade das relações sociais e dos valores defendidos como de primordial importância pela coletividade.

\section{CONCLUSÃO}

O pós-positivismo surge na segunda metade do século XX como resultado da confluência do jusnaturalismo e do positivismo jurídico, já que ao mesmo tempo em que confere importância ao direito posto, reinsere no âmbito do estudo do direito os valores morais e princípios, defendendo a necessidade de se entender que o direito não pode ser dissociado de seu conteúdo moral.

A partir da doutrina pós-positivista, a qual possui como grandes teóricos Ronald Dworkin e Robert Alexy, defende-se o valor normativo dos princípios e sua distinção com relação às regras e legitima-se a utilização de parâmetros de justiça e equidade para a solução de casos concretos. Entende-se, pois, haver a necessidade de uma a abertura valorativa do sistema jurídico, de modo a contrapor as premissas positivistas que deixavam em segundo plano considerações de natureza axiológica.

A abertura do debate filosófico contemporâneo a valores ético-políticos, proporcionado por referida corrente de pensamento, teve como um de seus resultados o surgimento do neoconstitucionalismo, novel movimento do direito constitucional contemporâneo que se desenvolveu contemporaneamente com os pensamentos pós-positivistas. 
Em contraposição ao constitucionalismo clássico, no qual as Constituições detinham caráter meramente instrumental, as novas Constituições passam a deter, a partir do neoconstitucionalismo, conteúdo material, aceitando a hegemonia axiológica dos princípios, os quais passam a ser considerados, segundo as ideias pós-positivistas, de fundamental importância nos novos sistemas constitucionais.

Com o neoconstitucionalismo, coloca-se a Constituição como centro do ordenamento jurídico, como pressuposto à efetividade e juridicidade do direito. Caracterizado pela inclusão de conteúdos morais em âmbito constitucional, pela atribuição de uma maior importância aos processos de aplicação dos direito, pela vinculação do legislador e aplicador do direito aos princípios constitucionais e pelo reconhecimento da normatividade e importância dos princípios, a partir do neoconstitucionalismo desenvolve-se um novo movimento constitucional, para assegurar o primado de valores ligados à ética e à justiça na solução de casos concretos, sem recorrer a valores metafísicos para tanto.

Desse modo, o neoconstitucionalismo, ao utilizar-se do pós-positivismo como embasamento jusfilosófico e, consequentemente, importar na irradiação dos valores abrigados nos princípios e regras constitucionais por todo o ordenamento jurídico, aufere meios para se compatibilizar o sistema jurídico com os valores defendidos pela sociedade contemporânea.

\section{REFERÊNCIAS}

ALEXY, Robert. Conceito e validade do Direito. Trad. Cergélia B. O. Mendes. São Paulo: WMF Martins Fontes, 2009.

Teoria dos Direitos fundamentais. Trad. Virgílio Afonso da Silva. São Paulo: Malheiros, 2008.

ÁVILA, Humberto. Neoconstitucionalismo: entre a "ciência do direito" e o "direito da ciência”. Revista Eletrônica de Direito do Estado. Salvador, n. 19, jan.-mar. 2009. Disponível em: <http://www.direitodoestado.com.br/rede/asp>. Acesso em: 18 jun. 2016. 
BARROSO. Neoconstitucionalismo e constitucionalização do Direito: o triunfo tardio do direito constitucional no Brasil. Revista de Direito Administrativo. Rio de Janeiro, v. 204, p. 142, abr.-jun. 2005.

BITTAR, Eduardo Carlos Bianca; ALMEIDA, Guilherme Assis de. Curso de filosofia do direito. 11 ed. São Paulo: Atlas, 2015.

BONAVIDES, Paulo. Curso de Direito constitucional. 24 ed. São Paulo: Malheiros, 2009.

COMANDUCCI, Paolo. Formas de (neo)constitucionalismo: un análisis metateórico. In: CARBONELL, Miguel (ed.). Neoconstitucionalismo. Madrid: Trotta; 2003.

DWORKIN, Ronald. Levando os Direitos a sério. Trad. Nelson Boeira. São Paulo: Martins Fontes, 2002.

FARALLI, Carla. A filosofia contemporânea do direito: temas e desafios. Trad. Candice Premaor Gullo. São Paulo: WMF Martins Fontes, 2006.

FERNANDES, Ricardo Vieira de; BICALHO, Guilherme Pereira Dolabella. Do positivismo ao pós-positivismo: o atual paradigma jusfilosófico constitucional. Revista de Informação Legislativa. Brasília, a. 48, n. 189, jan.-mar. 2011, p. 105-131.

FERRAJOLI, Luigi. Constitucionalismo garantista e neoconstitucionalismo. Disponível em: <http://www.abdconst.com.br/revista3/luigiferrajoli.pdf〉. Acesso em: 18 jun. 2016.

FLÓREZ-VALDÉZ, Joaquín Arces y. Los princípios generales del derecho y su formulación constitucional. Madrid: Civitas, 1990.

GROTIUS, Hugo. O direito da guerra e da paz. Trad. Ciro Mioranza. Florianópolis: Unijuí, 2004. 
HART, Hebert. O Conceito de Direito. Trad. A. Ribeiro Mendes. Lisboa: Fundação Caloustre Gulbenkian, 1996.

KELSEN, Hans. Teoria pura do Direito. Trad. João Baptista Machado. São Paulo: Martins Fontes, 1998.

MENDES, Gilmar Ferreira. BRANCO, Paulo Gustavo Gonet. Curso de Direito Constitucional. 9 ed. São Paulo: Saraiva, 2014.

MÖLLER, Max. Teoria geral do neoconstitucionalismo: bases teóricas do constitucionalismo contemporâneo. Porto Alegre: Livraria do Advogado, 2011.

POZZOLO, Susana. Neoconstitucionalismo y especificidad de la interpretación constitucional. In: Doxa, nº 21-II, 1998, p. 339-353.

SILVA, Paulo Maycon Costa da. O pós-positivismo do neoconstitucionalismo. Revista Direito e Liberdade. Rio Grande do Norte, v. 16, n. 1, p. 171-189, jan.-abr. 2014.

VALE, André Rufino do. Estrutura das normas de direitos fundamentais: repensando a distinção entre regras, princípios e valores. São Paulo: IDP/Saraiva, 2009.

- Aspectos do neoconstitucionalismo. Revista Brasileira de Direito Constitucional, n. 9, jan.-jun. 2007.

VIEIRA, Gustavo Adolfo Menezes. Interpretação constitucional e transconstitucionalismo: perspectivas sitêmicas. 2013. Dissertação (Mestrado em Direito Público) - Universidade Federal da Bahia, Salvador, 2013.

ZAGREBELSKY, Gustavo. El derecho dúctil: ley, derechos, justicia. Trad. Marina Gascón. Madrid: Trotta, 2007. 